\title{
ESCEPTICISMO Y DESACUERDO
}

\author{
RODRIGO LAERA \\ Universidad de Barcelona
}

\begin{abstract}
Within the framework of the epistemological debate on disagreement, this paper aims to examine the sceptical thesis that holds that, if it is impossible to rationally choose among two excluding positions, the only sensible or rational thing to do is to suspend judgement. The idea that ordinary life does not constitute the source of scepticism is presented, which rules out real disagreement between epistemic pairs as its foundation. Sceptical scenes differ ontologically from everyday scenes, without such ontological difference entailing an epistemic difference, since epistemic practices do not vary from one sceptical scene to other types of scenes.
\end{abstract}

Keywords: Disagreement; skepticism; Moorean argument; contextualism; evidence.

\section{Introducción}

Una de las cuestiones centrales en la epistemología actual es si el desacuerdo entre pares epistémicos conduce al escepticismo. La cuestión se vuelve todavía más relevante cuando se considera como eje del análisis teórico el desacuerdo entre quienes sostienen una posición escéptica y quienes sostienen una posición mooreana. En efecto, si el desacuerdo entre pares conduce a aceptar el escepticismo, entonces el desacuerdo entre quienes sostienen el argumento mooreano y quienes sostienen el argumento escéptico, dejará a los defensores de este último en una mejor posición epistémica. Por ello, importa tanto discutir la posición escéptica revisando sus argumentos y su viabilidad, como presentar el contraargumento de que el debate entre pares epistémicos que no llegan a un consenso, no implica que un evaluador imparcial deba suspender el juicio.

Pryor (2000) ha señalado que uno puede lidiar con la reflexión escéptica de manera ambiciosa o modesta. Un proyecto ambicioso es tratar de refutar al escéptico sobre sus propios términos, es decir, entrando en su propio juego de proponer altos niveles de escrutinio. Así, se establece racionalmente que, por ejemplo, uno posee dos manos usando las premisas que el escéptico permite. Un proyecto modesto consiste en establecer racionalmente que se puede creer y saber cosas como que uno tiene dos manos, sin entrar en contradicción con hechos evidentes acerca de procesos tan confiables como la percepción. La pretensión de este proyecto es la de desmantelar los argumentos escépticos apelando a las creencias preteóricas de la

Principia 16(1): 81-97 (2012).

Published by NEL — Epistemology and Logic Research Group, Federal University of Santa Catarina (UFSC), Brazil. 
percepción, sin aceptar las premisas que el escéptico necesita para su reflexión. Dentro de este marco, recientemente Leite (2010) cuestionó la tesis que sostiene que las fuentes de los argumentos escépticos se encuentran en las prácticas epistémicas de la vida diaria, es decir, criticó el movimiento de la reflexión que parte de las creencias ordinarias y que arriba a conclusiones escépticas.

Siguiendo a Stroud (1984), Leite da por sentado que los compromisos epistémicos de la vida diaria son falibles. Así, si los argumentos escépticos surgieran del corazón de la vida diaria, deberían excluir la demanda de certeza absoluta. Dado que esto no es posible, el fundamento del escepticismo no radica en vida diaria. La idea principal es que las sugerencias acercas de las hipótesis escépticas se basan en una petición de principio, pues están construidas de tal modo que ninguna de las evidencias diarias cuenta contra ellas. De esta manera, Leite comparte con Pryor $(2000,2004)$ la tesis de que hay una justificación empírica inmediata: las experiencias sensoriales pueden justificar una creencia de manera que no depende constitutivamente de que esté teniendo cualquier otra justificación acerca de otra creencia (cf. Neta 2004). Sin embargo, el autor también rechaza esta idea al considerar que es un error pensar que una teoría epistemológica es necesaria antes de participar en el tipo de respuesta al escepticismo. Por un lado, una respuesta contraria al escéptico, que funciona "desde dentro", afirmaría que se está legitimado a seguir ciertas normas y compromisos involucrados en las prácticas cotidianas. En cambio, las teorías epistemológicas pretenden aclarar, articular o sistematizar las características relevantes de nuestros hábitos tomándolos como pruebas suficientes para rechazar el escepticismo. Por otro lado, se puede aludir a la primacía de las prácticas epistémicas cotidianas y empezar a reflexionar desde ellas, sin que ningún argumento escéptico se ponga en marcha. Ambas posiciones presuponen que las hipótesis escépticas no son propias de la reflexión cotidiana ni nacen de ella.

Este artículo se propone examinar, desde el punto de vista del proyecto modesto, la conclusión de Leite tomando como referencia el argumento escéptico por el desacuerdo. Este argumento consiste en que, ante la imposibilidad de decidir racionalmente entre dos posiciones excluyentes, lo más prudente o lo único racional es suspender el juicio. Dicho de otra manera: suspender el juicio es la única respuesta racional para los casos de desacuerdo donde dos pares epistémicos tienen la misma evidencia y llegan a diferentes conclusiones. Sin embargo, esta conclusión pirrónica, si bien puede funcionar cuando las condiciones epistémicas son artificiales es decir, cuando los epistemólogos exponen un argumento u otro excluyendo sus implicaturas conversacionales - , deja de funcionar en el intercambio cotidiano de argumentos y en las prácticas epistémicas reales. ${ }^{1}$

En el siguiente apartado se considerarán dos argumentos que se excluyen: el escéptico y el mooreano, donde al haber un desacuerdo entre ambos, se llega a la conclusión de suspender el juicio. El escéptico tiene todas las de ganar. Considerando 
distintas propuestas a favor de uno y otro bando, en relación a este desacuerdo, en la práctica cotidiana, los agentes siguen manteniendo su postura epistémica. En el tercer apartado se sostiene que, aún si supiéramos que el argumento escéptico es el correcto o que somos cerebros en una cubeta o aún si creyéramos que lo más racional es suspender el juicio, las practicas epistémicas cotidianas (esto es la relación de los hombre con, por ejemplo, la adquisición de evidencias, la búsqueda de la verdad o la justificación de las proposiciones, etc.) no se verían afectadas. De tal modo, la idea que se propone es que el contraste entre estar en el mundo real y ser un cerebro en una cubeta no implica un cambio en las relaciones epistémicas del sujeto con su entorno, puesto que la diferencia entre un mundo y otro es solamente ontológica.

En síntesis, la meta de este ensayo no es falsear al escepticismo, sino articular dos tesis: (a) que la posición escéptica no es una proyección de las prácticas epistémicas cotidianas, por lo que el desacuerdo real no puede ser su fuente; y (b) que si bien los escenarios escépticos difieren ontológicamente de los escenarios cotidianos, esta diferencia ontológica no conlleva una diferencia epistémica, pues las prácticas epistémicas no varían de un escenario a otro.

\section{El desacuerdo como fuente del escepticismo}

Uno de los problemas epistemológicos centrales que se relaciona con el escepticismo es si uno sabe más de lo que cree saber o menos. En otras palabras, si uno debe o no debe creer o aceptar mucho de lo que se cree o se acepta sobre el mundo que lo rodea. El desafío que plantea este problema reside en la falta de un criterio para justificar por qué se sabe lo que se dice saber. Al margen de las disputas entre particularistas y metodistas, el problema escéptico pone en entredicho la compatibilidad de la reflexión filosófica con la vida ordinaria. A diferencia del examen escéptico, el examen mooreano acerca de los problemas epistemológicos distingue entre estas dos esferas del conocimiento. En efecto, cuando uno se compromete con un incontable número de creencias acerca de los hechos, el planteo puede ser de dos maneras diferentes: que la reflexión filosófica sea compatible con tales creencias o que sea un ámbito separado sin incidir en ellas. El escéptico no acepta ninguna de estos dos planteos, sino que pretende conseguir todo lo contrario: que la reflexión filosófica socave las creencias cotidianas, haciendo que el escrutinio sea cada vez más elevado.

En sus líneas principales de argumentación, tanto los juicios escépticos como los mooreanos descansan en un "argumentum ad ignorantiam":

1. si $S$ sabe $p$ entonces sabe $q$

2. $S$ no sabe $q$.

3. Luego, $S$ no sabe $p$.

Principia 16(1): 81-97 (2012). 
Así, el escéptico argumentará:

1. si $S$ sabe que tiene dos manos entonces sabe que no es un cerebro en una cubeta

2. $S$ no sabe si es un cerebro en una cubeta.

3. Luego, $S$ no sabe si tiene dos manos.

En cambio, quien sostenga el juicio mooreano argumentará:

1. si $S$ sabe que es un cerebro en una cubeta entonces sabe que no tiene dos manos

2. $S$ sabe que tiene dos manos.

3. Luego, $S$ no sabe que es un cerebro en una cubeta.

La conclusión del argumento escéptico radica en que si se contempla la posibilidad de ser un cerebro en una cubeta, entonces $S$ no posee razones para pensar ni si tiene o no dos manos. En cambio, el argumento mooreano concluye que si uno no sabe que es un cerebro en una cubeta, no hay razón para pensar que no tiene dos manos. De la misma manera que se es inocente hasta que se demuestre lo contrario, uno sabe que posee dos manos hasta que haya razones para sospechar que en realidad no las posee. Ambos argumentos son igualmente válidos aunque se contradigan. Ante esta contradicción, el escéptico puede continuar diciendo que, respecto a este tema, lo más adecuado es suspender el juicio. Y es lo más adecuado si uno no quiere correr el riesgo de equivocarse o de tomar una decisión irracional.

Frente a la posición anterior, el mooreano puede argumentar que hay una diferencia de plausibilidad en las conclusiones, pues no es lo mismo no saber que uno no tiene dos manos que no saber que no es un cerebro en una cubeta. Desde este punto de vista, a pesar de que el conocimiento acerca del mundo es falible, dicha falibilidad es más plausible que cualquiera de las premisas que pueden usarse en el argumento escéptico. Intuitivamente, parece mucho más razonable rechazar las sospechas escépticas que aceptar sus conclusiones. No obstante, la intuición está lejos de ser un criterio de razonabilidad o de mejor explicación: lo que puede ser intuitivo para uno, puede no serlo para otro. Fumerton (1992) sostuvo que la idea de que una explicación sea mejor que otra deja irresuelto el problema escéptico, ya que se necesita de un criterio para la elección de explicaciones alternativas y dicho criterio formará parte de las premisas desde las cuales se infiere la corrección de una explicación dada. Por un lado, cuando se trata con conjuntos de argumentos que compiten para ser mejores mediante algún criterio, resulta indispensable acordar cuál será ese criterio y si no puede ser objeto de las sospechas escépticas. Si lo fuera, entonces no serviría para refutar al escepticismo. Por otro lado, que un argumento sea mejor que otro de

Principia 16(1): 81-97 (2012). 
acuerdo con ese criterio no implica que se esté justificado para creer sin más que tal argumento sea el correcto. Si bien la apuesta más racional sería por el argumento vencedor, esta elección racional sólo implica que se acepta la mejor evaluación bajo determinadas circunstancias y estas también pueden llegar a ser sospechosas para la mente escéptica.

Más allá de buscar qué posición es más plausible mediante un determinado criterio, el desacuerdo entre mooreanos y escépticos presupone que ambos comparten el mismo espacio filosófico para que la discusión se lleve a cabo. Así, los dos acordarán que puede establecerse una distinción entre creencia mediata e inmediata: $S$ cree mediatamente que $p$, si cree en virtud de alguna relación entre esta creencia y alguna otra de $S$. En cambio, $S$ cree inmediatamente que $p$, si cree en virtud de algo que no sea una relación entre esta creencia y alguna otra de $S$. Dentro de este marco conceptual surge el desacuerdo. El escéptico entenderá que la creencia de $S$ de que tiene dos manos es mediata, pues involucra la creencia de que no es un cerebro en una cubeta. Por el contrario, el mooreano considerará a la creencia de $S$ como inmediata, al producirse perceptivamente. Es importante tener en cuenta, en beneficio del contextualista, que afirmar de una creencia que es inmediata no implica que no pueda llegar a ser mediata. La creencia de $S$ puede sostenerse a partir de su percepción, pero también puede ser producto de la reflexión y ambas fuentes pueden ser compatibles. Si el nivel de escrutinio es alto - ya que se consideran más posibilidades para su evaluación-, la fiabilidad de la percepción dependerá de la fiabilidad de otro proceso, el de reflexión (por ejemplo, la inducción). En cambio, cuando el nivel de escrutinio es bajo - es decir, que alcanza con las creencias inmediatas - la fiabilidad de la percepción por sí sola es suficiente para dirimir cuestiones tales como la creencia de $S$. Así, la creencia inmediata puede identificarse con el conocimiento básico. La estructura de este tipo de conocimiento es la siguiente: $S$ tiene un conocimiento básico de $p$ sólo en el caso de que el conocimiento de $p$ sea anterior al conocimiento de la fiabilidad de la fuente cognitiva de $S$. Por ejemplo, $S$ cree que tiene dos manos inmediatamente y, a la vez, $S$ lo sabría antes de saber que la percepción es una fuente fiable. El escepticismo cuestiona la creencia de $S$, apelando a la idea de que no puede haber conocimiento que sea anterior al conocimiento de la fiabilidad de la fuente de donde procede: rechaza tanto la idea de la creencia inmediata como la del conocimiento básico. No obstante, la vida diaria está plagada de creencias inmediatas y de conocimientos básicos, por lo que la fuente del escepticismo no radicaría en la vida diaria. Un sólo ejemplo alcanza para darse cuenta de ello: $S$ lee una noticia frívola en el periódico como la de que el Fútbol Club Barcelona ganó el domingo, $S$ dice saber lo que el periódico dice — "sé que el Barcelona ganó el domingo"-, y dice saberlo antes de saber si la fuente es fiable. Cuando se manipulan las noticias en los periódicos y en los telediarios, se asume que los hombres tienden cotidianamente al conocimiento básico. ${ }^{2} \mathrm{El}$ conocimiento 
básico, como el inmediato, no requiere pruebas. Sin embargo, no hay que confundir pruebas con evidencia. Uno podría adquirir evidencias a través de la experiencia, la inducción o la memoria y tales evidencias pueden ser importantes para la obtención de conocimiento, aunque no constituyan pruebas. La idea es que $S$ puede no dar una prueba acerca de que tiene dos manos, pero esto no es razón suficiente para pensar que sea falsa o que no haya evidencias a favor de la creencia de $S$. Se puede aceptar $p$ sin saber exactamente por qué. ${ }^{3}$

El escéptico puede estimar que si $S$ cree $p$ sin tener una adecuada razón para suponer que es verdadera, entonces viola una obligación intelectual. Sin embargo, hay que distinguir estar obligado a algo con tener permitido hacer algo. Uno tiene permitido ir a trabajar en automóvil sin estar obligado a ello, aunque sí esté obligado a parar cuando el semáforo está en rojo. Dejando de lado el debate acerca del voluntarismo, del mismo modo que se puede decir que a $S$ le está permitido creer que tiene dos manos aunque no esté obligado a ello, a $S$ le está permitido creer que no tiene dos manos sin tampoco estar obligado a ello. En ninguno de los dos casos se viola una obligación intelectual. Si la obligación es dar una razón adecuada que justifique su experiencia de que tiene dos manos, la pregunta es ¿por qué es una obligación? ¿Acaso en el contexto de la vida no alcanza con la experiencia? Véase el siguiente ejemplo tomado de Feldman (2005): ${ }^{4}$ supóngase que $S$ es alumno en la universidad y tiene la primera clase de la asignatura de Teoría del Conocimiento. En esta asignatura el profesor expone los argumentos escépticos por los que no hay buenas razones para pensar que la experiencia perceptual es causada por los objetos físicos. Ahora, a $S$ esos argumentos le resultan convincentes. Sin embargo, cuando $S$ sale de la clase y ve que hay un árbol delante, no considera que lo que ve en realidad no es tal, influenciado por los argumentos de la clase. Por el contrario, mantiene sus anteriores creencias acerca de la experiencia perceptual. Dado que en este caso se trata de dos niveles de escrutinios diferentes - el de la clase de filosofía y el cotidiano - la evidencia exigida en uno y otro caso puede variar de acuerdo a los compromisos epistémicos entre personas. Antes de la clase, $S$ está justificado en creer $p$ ya que tiene suficientes evidencias para ello, pero después de la clase adquirió evidencias suficientes como para sostener no- $p$. No obstante, esta evidencia no afecta a la anterior, debido a que le exige intelectualmente a $S$ más de lo que $S$ puede dar en la vida diaria. La exigencia intelectual debe adecuarse a un contexto, uno no puede ser exigente donde nadie lo es. Las exigencias tienen sentido siempre y cuando haya alguien que atienda a ellas. Supóngase que $S$ es maestro de un colegio y tiene que evaluar la redacción de niños de 10 años. Evidentemente el nivel de exigencia se ajustará a ese contexto y no tiene sentido evaluarlos de acuerdo con el nivel que se espera de adultos universitarios. Si nadie cumple con el nivel de exigencia, el problema no radica en los sujetos que participan, sino en quienes imponen semejante nivel.

Principia 16(1): 81-97 (2012). 
Si en la vida diaria nadie evalúa las posibilidades escépticas, entonces cualquier discusión en torno a ellas compartirá el mismo contexto de reflexión, y las soluciones contextualistas no serían adecuadas a raíz de un error de base. En efecto, el contextualista intenta eludir la disputa dándole cierto crédito epistémico al escéptico, pero al intentar eludirla se encuentra involucrado en ella. Como sostuvo DeRose (2004), si sólo hubiera un único espacio de reflexión, el escéptico negaría lo que su oponente intenta afirmar y el debate sería de ida y vuelta. ${ }^{5}$ El desacuerdo se produce debido al presupuesto de que las posiciones acuerdan sobre un tema. En ese sentido, el escéptico presupone una base para el desacuerdo, de tal manera que se aleja del contextualismo. Justamente, el contextualista se refiere a dos espacios diferentes de razones, el de la reflexión diaria y el de la filosófica, donde la evaluación semántica de saber - y, con ello, las exigencias necesarias para que una proposición alcance ese estatus - cambia. Mientras, el escéptico considerará que, aún compartimiento la misma evaluación semántica del término saber, subsiste el desacuerdo. Por lo tanto, lo más atinado para un observador neutral es suspender el juicio.

El escéptico puede ir más allá y sostener una suerte de conservadurismo: $S$ puede adquirir una creencia justificada de que $p$ sobre la base de $E$ sólo si tiene una justificación independiente para creer que todas las hipótesis escépticas que socavan el apoyo prestado por $E$ a $p$ son falsas. ${ }^{6}$ Una solución posible para evitar este conservadurismo reside en señalar que las premisas escépticas se basan en argumentos que se refutan a sí mismos. La estrategia de esta solución consiste en subrayar que las hipótesis escépticas están construidas de tal manera que neutralizan las evidencias cotidianas. Así, si $S$ está siendo engañado por un genio maligno, entonces su fiabilidad, competencia o su autoridad se ven comprometidas en una amplia gama de asuntos, incluso en cosas tales como la existencia de algún genio maligno. De tal manera, si se necesitan evidencias independientes de las circunstancias de $S$ para evaluar las hipótesis escépticas, entonces el escepticismo tampoco es viable, pues niega la existencia de evidencias independientes. Leite (2010) ha rechazado esta suerte de solución, argumentando que no se necesita tener evidencias independientes para que uno crea, a través de un aceptable curso de razonamientos, que no hay genios malignos que empleen toda su astucia para engañarnos. De hecho, esta solución consolida aquello que pretende rechazar. El escéptico no afirma que $S$ es un cerebro en una cubeta, sino que $S$ puede llegar a ser un cerebro en una cubeta. Para decirlo a la manera de Hume, en el dominio de la contingencia propia de las cuestiones de hecho no hay nada que diga que $S$, necesariamente, no es un cerebro en una cubeta. Por lo tanto, que la autoridad o fiabilidad de las evidencias para decidir la existencia de genios malignos no implica que no los haya. Es más, reconocer que hay genios malignos y que lo más atinado sea suspender el juicio, no implica que uno siempre elija lo más atinado. A menudo se da el caso de que la evidencia que se usa para confirmar una creencia no es la que un evaluador neutral consideraría 
racionalmente como la mejor disponible.

Aquí el escéptico puede conducir su argumentación apelando a casos de tipo Gettier: $S$ está conduciendo su auto por la carretera. A lo lejos, ve algo que parece ser un granero. Ante esta percepción, cree que está viendo un granero. Sin embargo, desconoce que en la región tienen la costumbre de construir falsos graneros, que sólo tienen la fachada que se ve desde la carretera. Pese a todo, por casualidad, lo que $S$ había visto era en realidad uno de los pocos casos de verdaderos graneros en la zona. En este caso, $S$ no tiene razón para sospechar que lo que ve es un granero, aunque no sea un granero lo que ve, de la misma manera que $S$ no tiene razón para sospechar que lo que ve es un granero, aunque afortunadamente resulte ser un granero. Casos como estos llevan a pensar que no hay nada en el dominio de la experiencia visual cuando $S$ conduce por la carretera que incluya la posibilidad de que haya graneros falsos. De hecho, aunque $S$ se haya dado cuenta, finalmente, de que su experiencia visual acerca de los graneros haya sido falseada, su comportamiento epistémico respecto a los graneros no cambiaría. No se volvería un escéptico respecto a la presencia de graneros. Por ejemplo, $S$ podría volver un tiempo después a conducir por otra carretera donde haya graneros y no sospecharía que lo que está viendo no son graneros sobre la base de que la experiencia pasada resulto falsa. Para que esto ocurra, los ejemplos de graneros falsos deberían presentarse con cierta frecuencia. En tal caso, tampoco podemos decir que la inadecuación entre la experiencia visual y los graneros fuera accidental o afortunada. Y esto es porque los casos de tipo Gettier - casos en los que se escrutan circunstancias inesperadas - , presuponen la existencia de un evaluador imparcial que tiene a disposición un conjunto de información que el protagonista no posee.

Supóngase que $S$ tiene un gran número de evidencias que fundamentan la creencia de que $p$ es el caso y no posee evidencia en contra de ello. Además, supóngase que la evidencia resulta incompleta porque $S$ no empleó un argumento que conocía cuya conclusión niega $p$, de tal manera que $S$ pierde una pieza adicional de evidencia. Ahora bien, esta pérdida no muestra que su creencia sea irracional o que no deba ser tomada como conocimiento. Si no es posible considerar todas las evidencias, aunque sí algunas de ellas, ¿qué es lo que determina que unas sean relevantes y otras no? Si la evaluación de una evidencia nunca es completa, ¿cómo saber si la evidencia faltante es crucial para llegar a un cierre en torno al problema escéptico? Como ya se dijo, la tesis de este ensayo es que la evidencia faltante no es crucial. Justamente, la sospecha escéptica nace en la suposición de que siempre se necesita alguna evidencia adicional para escrutar si la fuente es adecuada a la creencia. Nunca alcanza con la evidencia que uno posee y alcanzar el conocimiento se convierte en un asunto complicado. Si la justificación de que $S$ tiene dos manos proviene de la aceptación implícita de hipótesis tales como la de que no es un cerebro en una cubeta, entonces $S$ no necesita reflexionar acerca de la fiabilidad de sus fuentes cognitivas para 
saber si tiene dos manos. Dicho de otra manera, si las facultades son fiables sobre la base del conocimiento básico de cada individuo, entonces la evidencia de primer orden se vuelve una condición indispensable para la producción de conocimiento en la vida diaria. De la misma manera que $S$ cree racionalmente $p$ o no- $p$ dependiendo de lo que otras personas racionalmente crean, $S$ adquiere evidencias y las evalúa de acuerdo a la forma de adquirir y evaluar evidencias de la comunidad epistémica a la que pertenece. Si la evidencia siempre es inconclusa en la vida diaria, considerar la hipótesis de ser un cerebro en una cubeta antes que otras hipótesis más cercanas es una decisión tan apragmática que no deja de parecer ridícula.

Nuevamente, el desacuerdo estriba en que el mooreano dice que sabe que tiene dos manos y no sabe que es un cerebro en una cubeta, mientras que el escéptico sostiene que, mientras no sepamos que no somos un cerebro en una cubeta, no podemos saber que tenemos dos manos. Lo dicho hasta el momento se ocupa únicamente del evaluador externo y de cuál es la decisión correcta entre dos posiciones confrontadas respecto al problema del escepticismo. El desacuerdo no solamente puede surgir entre mooreanos, escépticos y un evaluador externo, sino también entre pares evaluadores. Dos personas cuentan como pares evaluadores con respecto a una cuestión dada o a una proposición, si comparten la misma evidencia relevante y tienen habilidades intelectuales comparables que sean pertinentes a esa cuestión o proposición. Esto es: (a) que haya igualdad con respecto a la familiaridad con la evidencia y a los argumentos en los que se desarrolla la cuestión y (b) que quienes desacuerdan sean iguales con respecto a las virtudes epistémicas como la inteligencia, la reflexión y la libertad de prejuicios. Si (a) y (b) son condiciones para un genuino desacuerdo en la vida cotidiana, entonces Leite tiene razón y el escepticismo no se corresponde con la manera en que los hombres se relacionan con el mundo. Por un lado, porque dado que el escepticismo requiere de un desacuerdo entre pares surge el problema de los criterios para reconocer a ese par. Tal reconocimiento depende no sólo de las credenciales que posea cada uno de los miembros, sino también de aspectos subjetivos por los cuales se valoran o se tienen en cuenta esas credenciales. Por otro lado, para que el desacuerdo sea la fuente del escepticismo, los pares epistémicos deben mantenerse constantes en sus argumentos, sin que un evaluador pueda decidirse por alguno racionalmente. Pero esto es posible si ambos pares son dogmáticos manteniendo sus posturas, por lo que en este caso el escepticismo dependería de cierto dogmatismo.

Los pares evaluadores pueden reflexionar acerca del argumento mooreano y del argumento escéptico sin ponerse de acuerdo acerca de las razones por las cuales aceptan sus posturas, aunque se trate de la misma. Dada esta situación hay dos posibilidades. La primera, que haya un acercamiento entre las partes, puesto que cada uno admite la posibilidad de que su par tenga razón, ajustando la credibilidad inicial en la dirección contraria para converger en una misma actitud. ${ }^{7}$ La segunda, que cada una de las partes siga manteniendo su postura, a pesar de las razones 
dadas por su adversario; el mundo está lleno de obstinados. ${ }^{8}$ Volviendo al ejemplo del estudiante de filosofía: de tener en cuenta la primera posibilidad, $S$ cambiaría de opinión respecto a lo que cree saber del mundo físico, es decir cambiaría su conocimiento de segundo orden, no sabría lo que creía saber. De acuerdo con la segunda posibilidad, $S$ mantendría su creencia original, sin cambiar el conocimiento de segundo orden: seguiría sabiendo lo que creía saber. Sin embargo, es probable que a $S$ le pasen las dos cosas dependiendo de las circunstancias. Por ejemplo, en la clase de filosofía sería consciente de que sabe que no sabe algo acerca del mundo sensible, pero en la vida cotidiana seguramente si a $S$ se le pregunta si hay un árbol delante diría que sí, cuando lo ve, y que no, cuando no lo ve. Y si se le pregunta por qué, es muy probable que diga, olvidando la clase de filosofía, "porque lo veo".

Uno puede estar, entonces, tentado a concluir lo siguiente: si $S$ tiene una experiencia que representa $p$ y no tiene motivos dentro de su dominio (el ámbito de la vida diaria) para sospechar de ella, entonces está justificado en creer que $p$. Si bien esta idea puede llegar a ser atractiva, debe ser matizada. Aunque ninguna evidencia falsee la creencia, ello no excluye la posibilidad de que haya evidencias que sí las falsee. De manera análoga al caso anterior $S$ ve un granero y recoge el testimonio de que en la zona hay graneros falsos, $S$ puede estar inclinado a pensar que si vio un granero fue de manera accidental. Pero también puede hacer caso omiso del testimonio y seguir pensando, simplemente, que vio un granero, un fenómeno al que Foley y Fumerton (1982) llamaron "indolencia epistémica". En efecto, uno puede pensar que la evidencia - sobre todo la empírica - contra los argumentos esgrimidos conduce a moderar las opiniones sobre esos argumentos, pero ¿cómo conciliar la opinión del escéptico con las del mooreano? La teoría de la conciliación presupone el siguiente principio: que en la evaluación de las credenciales epistémicas de las creencias de otra persona sobre $p$, modificar la propia creencia acerca de $p$ requiere esgrimir razones independientes de las que dieron lugar a la creencia propia e inicial de $p$. La respuesta conciliadora parte de este principio y asume además que las disputas propias de la evaluación dan razones de peso para pensar que la otra persona ha evaluado las pruebas correctamente. Por lo tanto, con lo cual se debe, en el caso de que uno esté bastante seguro de que $p$ y que la otra persona es la misma confianza en que $p$, se debe suspender la creencia en $p$ (Christensen 2009); como mínimo debe admitirse la posibilidad de que la creencia propia inicial sea incorrecta. Por ejemplo, $S$ revisa sus puntos de vista debido a que reconoce la ventaja epistémica del profesor. Sin embargo, el profesor influirá epistémicamente sólo dentro del contexto de la universidad, dando razones de peso a $S$ para que reconsidere sus creencias, razones que serán distintas e independientes de aquellas que $S$ tenía inicialmente. El resultado puede ser que, en efecto, $S$ se acerque en ese momento a la posición escéptica de su profesor, aunque fuera de la clase las razones escépticas perderán su fuerza y el estudiante volverá más o menos tranquilamente a sus creencias iniciales.

Principia 16(1): 81-97 (2012). 
No hay una única respuesta a qué es lo que ocurre cuando un par epistémico le da una razón a $S$ para sospechar, dentro del dominio pertinente, que $p$ es falsa. En realidad $S$ responderá según la creencia de la que se trate, dependiendo tanto de cuán afianzada esté en sus costumbres, como de las circunstancias que atraviese. Justamente, Foley (2004) sostuvo que es un error pensar los conflictos - como el que mantienen el mooreano y el escéptico - en términos de un modelo de arbitraje neutral. Esto es, presuponer como punto de partida que los argumentos están sujetos a una evaluación libre de simpatías, compromisos o intereses personales de quien los exhibe o evalúa y que, mediante una deliberación desinteresada, los agentes epistémicos eligen el argumento más racional. Estas condiciones ideales no se producen más que como presupuesto en la mente de quien escribe acerca de estos temas aunque quienes escriban y escruten o evalúen estos temas, generalmente, han ido a la universidad, poseen estados psicológicos, ideologías, etc. De esta manera, ni el estudiante de filosofía ni el profesor son neutrales, incluso obviando la relación jerárquica que existe entre ambos.

En suma, el análisis en tercera persona bajo el presupuesto de neutralidad omite, por un lado el desacuerdo real que muchas veces surge, no sólo en la vida cotidiana, sino entre filósofos; y por otro lado, que, en ocasiones, resulta imposible alcanzar consensos en relación a determinados temas. Si el desacuerdo real surge entre pares intelectuales, a pesar de haber estado expuestos a la misma evidencia, entonces un acuerdo para el desacuerdo parece de difícil aplicación en el mundo cotidiano. Es más, si el objetivo de la argumentación que da lugar al desacuerdo es la persuasión, poco importa si los consensos se alcanzan mediante las ventajas epistémicas. Sin embargo, puede pensarse que el resultado del desacuerdo no conduce a la conclusión escéptica, como tampoco al cambio del punto de vista original. Si hay un total desacuerdo, cada una de las partes puede, sin pérdida de racionalidad, mantener su postura, de la misma manera que con el tiempo y de manera no consciente puede cambiarla. El profesor escéptico escucha las razones que dan sus alumnos acerca de la fiabilidad de sus percepciones, pero no por eso pone en duda o modifica su escepticismo. Tampoco tiene por qué ocurrir lo contrario: $S$ puede escrutar los argumentos escépticos que falsean la evidencia disponible acerca de sus creencias perceptuales, y no por eso deja de sostener su punto de vista. Mantener el punto de vista frente a pares que dan razones no lleva necesariamente a caer en el escepticismo ni constituye una pérdida de racionalidad. De la misma manera, postular dudas respecto a un tema no implica que lo más acertado sea suspender el juicio. Uno puede tener muchas dudas acerca de algo, pero ser lo suficientemente temerario para sostener su punto de vista sin revisarlo y, a la larga, tener razón. El desacuerdo no es motivo suficiente por lo cual uno deba ser escéptico. 


\section{La irrelevancia del escepticismo respecto a las prácticas epistémicas cotidianas}

Generalmente, el escepticismo ha representado un problema para todo externista. No obstante, la peculiaridad del caso escéptico es que no se puede estar de acuerdo acerca de los hechos, simplemente porque no hay hechos sobre los cuales acordar. Aun presuponiendo que los hechos existan tal como el mooreano los presenta, el escepticismo parece recomponerse en otra dimensión epistémica. Esto se puede examinar de la siguiente manera: $S$ y su gemelo, $S G$, tienen los mismos estados mentales, de tal manera que si uno ve un árbol, el otro también lo ve. Asimismo, $S$ vive en este mundo y $S G$ es un cerebro en una cubeta; por lo tanto, en el contexto de $S$ la hipótesis mooreana es verdadera, mientras que la escéptica es falsa. Por el contrario, en el contexto de $S G$ la hipótesis mooreana es falsa, mientras que la escéptica es verdadera.

Ahora bien, la cuestión fundamental aquí es que en el entorno de $S G$ las relaciones epistémicas no parecen ser distintas que las del entorno de $S$. Lo que sí parecería ser distinto es el estatus ontológico que se le adjudica - partiendo de un determinado análisis metafísico - a ambos contextos. Siguiendo con el ejemplo de Feldman (2005), supóngase que $S G$ es consciente de que es un cerebro en la cubeta, que de alguna manera sabe (ya sea por una especie de revelación o por lo que fuere) que la hipótesis escéptica es verdadera. Entonces, uno podría preguntarse qué significa ser mooreano o ser escéptico para $S G$. La cuestión planteada es, por lo tanto, si somos cerebros en una cubeta dentro de un cerebro en una cubeta - la posición escéptica - o si simplemente somos cerebros en una cubeta - la posición mooreana - (se podría incluso seguir hasta el infinito). Es decir, un mooreano dentro de un cerebro en una cubeta sostendrá que sí tiene dos manos (virtuales), mientras que un escéptico dentro de un cerebro en una cubeta dirá que no puede estar seguro de ello. Por ejemplo, si $S G$ es mooreano podría argumentar que su percepción es evidencia suficiente de que tiene dos manos (virtuales) en el dominio de ser un cerebro en una cubeta. Pero si $S G$ es escéptico puede fundamentar su posición de dos maneras: una manera consiste en negar que es un cerebro en una cubeta, ya que se puede ser escéptico respecto al escepticismo; alternativamente, puede pensar que lo que ve no son en realidad sus manos (virtuales), sino que además de ser un cerebro en una cubeta hay un genio maligno que lo engaña. Es decir, puede haber un escepticismo de segundo orden. Quizás esta idea, un poco intrincada, arroje alguna luz acerca de la naturaleza de las hipótesis escépticas y de cómo funcionan.

De este modo, es posible distinguir entre el externismo y el internismo de la evidencia: el externalismo de la evidencia sostiene que es posible que $S$ y $S G$ no tengan la misma evidencia, en cambio el internalismo sostiene que tienen la misma 
evidencia. De acuerdo con lo dicho, el internismo de la evidencia parece correcto, ya que presupone que una vez que el contenido de los estados internos es fijado, la evidencia no depende del entorno. Ambos, $S$ y $S G$, al poseer el mismo contenido representacional, tienen idénticas evidencias, independientemente del marco metafísico en el que se hallen. Por lo tanto, $S$ se relacionará con el mundo externo en el mundo real y $S G$ relacionará de la misma manera con el mundo externo en el mundo virtual. Incluso si se sostiene la tesis de Williamson (2002) y se entiende que la evidencia es conocimiento, la evidencia no dejaría de ser una relación entre el sujeto y su entorno, porque las relaciones con el entorno propias de $S$ y $S G$ no se ven afectadas por la diferencia de ser o no un cerebro en una cubeta.

A grandes rasgos, el escepticismo ataca las evidencias de primer orden, cuestionando las de segundo orden (es decir, las evidencias acerca de las evidencias). Desde el enfoque externista, el escepticismo ataca - verbigracia - las condiciones por las cuales la fuente del conocimiento es fiable. Precisamente, parte del atractivo del fiabilismo radica en la noción de que la gente puede conocer algo (o tener una creencia justificada) sin saberlo todo sobre la fiabilidad del proceso que genera la creencia. Este conocimiento de primer orden acerca del mundo no depende de un conocimiento de segundo orden. Del mismo modo, si la evidencia se basa en un proceso fiable, no es necesario conocer la evidencia acerca de la evidencia - una evidencia de segundo orden - para garantizar la fiabilidad de dicho proceso.

La presentación de una serie de evidencias de segundo orden que falseen o refuten las de primer orden, cuestiona la fiabilidad de los procesos como razón suficiente para desplazar las dudas escépticas radica en. El escéptico cobra fuerza ante la posibilidad de que todas las evidencias de primer orden, aunque sean fiables, sean falseadas por las del segundo. Considérese el problema de la generalidad como recurso escéptico. Este problema, a grandes rasgos, alude a que no se posee una idea clara de cómo individuar las creencias que forman los procesos fiables. Cada proceso que causa una creencia particular es de muchos tipos diferentes, que abarcan distintos grados de certidumbre. La secuencia de eventos que sirven de evidencia para sostener la creencia de que hay árbol de arce en frente de $S$ pueden estar caracterizada al menos de las siguientes maneras: una la creencia de formación visual que inicie el proceso, la retina que producen la imagen con sus características específicas y que conducen a la creencia de que hay un árbol de arce en frente, el proceso de contar con una forma de la hoja para formar un juicio acerca de la clasificación de árboles, el proceso de percepción de clasificación de las especies de un árbol situado detrás de una obstrucción sólida, etc. Los tipos de procesos no tienen límites. Son tan numerosos como las propiedades que influyen en el proceso. Por lo tanto, la cuestión acerca de las evidencias basadas en procesos de fiabilidad debe enfrentar la cuestión de qué tipo de procesos debe ser fiable para que la creencia de $S$ resulte justificada. Si no se individua qué proceso resulta fiable, entonces tampoco se indivi- 
duarán las evidencias que sostienen una creencia. Pero, y he aquí lo importante, este problema prevalece, tanto si $S$ estuviera en el mundo real como si fuera un cerebro en una cubeta. Dicho de un modo más simple, el problema de la generalidad en tanto evidencia presentada por el profesor escéptico a $S$ socavando sus creencias perceptuales - ocurre tanto si $S$ está en el mundo real como si es un cerebro en una cubeta. ${ }^{9}$ Y más aun, iincluso el desacuerdo entre mooreanos y escépticos subsiste tanto en el dominio de $S$ como en el dominio de $S G$ !

Una vez más, la percepción será una fuente fiable para determinar si hay un árbol delante, en el caso de $S$ y de $S G$, para cada uno en su contexto. La respuesta de ambos es la misma: "tengo un árbol delante siendo yo un cerebro en una cubeta" para un cerebro en una cubeta, tiene el mismo valor epistémico que "tengo un árbol delante estando yo en el mundo externo" para un sujeto en el mundo externo. Así, ser fiable o falible en el mundo real es una función idéntica a ser fiable o falible en el mundo de los cerebros en una cubeta. Por ejemplo, si el termómetro es fiable en la vida externa de $S$, el termómetro de los cerebros en una cubeta también es fiable para la vida interna de $S G$. La función propia en uno y otro caso no cambia. ${ }^{10}$ Pero ¿qué quiere decir vivir una vida externa o una vida interna? Quiere decir que, en un caso, las cosas son, mientras que en el caso de los cerebros en una cubeta parecen ser. Y la diferencia entre ser y parecer, desde Parménides, es una diferencia ontológica.

Llegados a este punto del análisis resulta imprescindible considerar si tal diferencia ontológica tiene consecuencias epistémicas. Cuando $S G$, por medio de una revelación o de lo que fuera, advierte con seguridad que no existe nada fuera de su mente, ¿qué actitud tomaría entonces? ¿Dejaría de hablar con aquellas personas que sólo están en su mente? ¿Se pegaría un tiro? Lo más probable es que advirtiera que también la bala y el revólver son entidades mentales y, por lo tanto, que las consecuencias podrían ser las mismas que el mundo real. ¿Qué ocurriría si $S G$ comunica lo que le fue revelado a las personas que están en tu mente y le dice que no son reales? ¿Acaso alguien le creería? ¿Cómo decirle a alguien que no es real? Desde luego, nadie lo tomaría en serio. Aun más, $S G$ podría haber obtenido el conocimiento de que es un cerebro en una cubeta mediante alguna revelación proveniente de alguna entidad externa; en ese caso podría pensar que hay algo más que sus estados mentales. Luego, pensaría que existe algo que es independiente de su mente. Y si esto fuera también una artimaña propia de su estado mental, el argumento se contradice a sí mismo, pues si algo en su estado mental le revela que no existe nada excepto su estado mental, no tiene por ello una garantía de que así sea. Si se da el caso de que tuviera esa garantía, sus acciones no cambiarían en mucho de lo que ahora son. Es decir, si $S G$ sabe que un coche que no existe ocasiona el mismo dolor que uno que sí existe cuando lo atropella, entonces tendrá el mismo cuidado en cruzar la calle que no existe, que al cruzar la calle que sí existe. Como su actitud ante los hechos no cambiaría mucho, lo más probable es que se fuera perdiendo en el trato con la vida 
cotidiana, disfrutando, deseando, etc. de las cosas irreales, de la misma manera que lo hace $S$ con las reales. También su revelación estaría condenada a no ser creída o al silencio, porque al ser un sinsentido decirle a alguien irreal que es irreal, no tendría a quién comunicarlo. Igualmente, policías irreales le pondrían multas de tráfico irreales al saltarse irrealmente un semáforo irreal; multas que seguramente también pagaría irrealmente con dinero irreal, etc. Y, finalmente, la distinción entre lo real e irreal se desplazaría a un segundo orden o se diluiría.

La racionalidad epistémica depende del respeto que se tenga por la evidencia; por lo tanto si $S$ resulta ser un cerebro en una cubeta o no, en cualquier caso deberá guiarse no por la evidencia ontológica de base, sino por la evidencia epistémica con la cual le toca tratar.

\section{Conclusión}

Uno de los objetivos de este artículo fue exponer la idea de que la persistencia en el desacuerdo no tiene por qué culminar en la posición pirrónica de suspender el juicio. El desacuerdo real - aquel que se produce en una situación cotidiana de intercambio comunicativo - , contrariamente al de tercera persona - el análisis del desacuerdo presuponiendo la decisión de un observador y evaluador imparcial - , consiste en que se considera que uno comparte la misma evidencia disponible, resultando de ella dos puntos de vista contrapuestos sin llegar a la suspensión del juicio.

El escepticismo no tiene cabida en las reflexiones en de la vida cotidiana. Si alguien quiere reflexionar sobre el escepticismo, debe percatarse de que se encuentra en un dominio epistémico distinto al de la vida cotidiana. Se trata de una cuestión de límites en torno a la reflexión: el escepticismo es el límite de la reflexión acerca del contexto de la vida diaria. ${ }^{11}$ Una sencilla muestra de por qué el escepticismo constituye un límite intelectual es que, si el escéptico tuviera razón y $S$ supiera que es un cerebro en una cubeta, las relaciones de $S$ con aquello que constituye una evidencia en su mundo virtual no cambiarían. Ya sea desde el contexto de un cerebro en una cubeta o de sujeto en el mundo real, lo que es evidente en un contexto lo es para aquello que se encuentra relacionado con el dominio de esa evidencia para ese contexto. Así, se establece un nuevo límite para la reflexiones de $S$, que podría plantear ahora un escepticismo en el dominio de los cerebros en una cubeta. De acuerdo con esto, las discusiones escépticas subsistirán independientemente del contexto ontológico en el que ocurran, tanto si se trata del mundo real como si se trata del mundo aparente de los cerebros en una cubeta. Finalmente, si bien lo argumentado hasta aquí sugiere que el cambio de contexto ontológico no constituye un cambio de contexto epistémico, dicha perspectiva todavía queda abierta a estudios posteriores. $^{12}$

Principia 16(1): 81-97 (2012). 


\section{Referencias}

Christensen, D. 2009. Disagreement as Evidence: The Epistemology of Controversy. Philosophy Compass 4: 756-67.

- 2007. Epistemology of Disagreement: the Good News. Philosophical Review 116: 187-217.

Cohen, S. 1984. Justification and Truth. Philosophical Studies 46: 279-95.

DeRose, K. 2004. Single Scoreboard Semantics. Philosophical Studies 119: 1-21.

Elga, A. 2007. Reflection and Disagreement. Nous 41: 478-502.

Feldman, R. 2005. Respecting the Evidence. Philosophical Perspectives 19: 95-119.

Foley, R. 2004. Intellectual Trust in Oneself and Others. Cambridge: Cambridge University Press.

Foley, R., \& Fumerton, R. 1982. Epistemic Indolence. Mind 91: 38-56.

Furmerton, R. 1992. Skepticism and Reasoning to the Best Explanation. Philosophical Issues 2: 149-69.

Kelly, T. 2005. Epistemic Significance of Disagreement. In T. S. Gendler, \& J. Hawthonrne (eds.) Oxford Studies in Epistemology, Vol. 1. Oxford: Oxford University Press, pp. 16796.

Leite, A. 2010. How to Take Skepticism Seriously. Philosophical Studies 148: 39-60.

Neta, R. 2004. Perceptual Evidence and the New Dogmatism. Philosophical Studies 119: 199214.

Pryor, J. 2000. The Skeptic and the Dogmatist. Nous 34: 517-49.

_. 2004. What's Wrong with Moore's Argument? Philosophical Issues 14: 349-78.

Silins, N. 2007. Basic Justification and the Moorean Response to Skeptic. In T. Gendler, \& J. Hawthorne (eds.) Oxford Studies in Epistemology, Vol. 2. Oxford: Oxford University Press, pp. 108-40.

Stroud, B. 1984. The Significance of Philosophical Skepticism. Oxford: Oxford University press. Willenken, T. 2011. Moorean Responses to Skepticism: A Defense. Philosophy Studies 154: $1-25$.

Williamson, T. 2002. Knowledge and its Limits. New York: Oxford University Press.

$$
\begin{array}{r}
\text { Rodrigo LAERA } \\
\text { Universidad de Barcelona } \\
\text { Departamento de Filosofía Contemporánea } \\
\text { EsPANHA } \\
\text { r.laera@ub.edu }
\end{array}
$$

Resumo. No marco do debate epistemológico acerca do desacordo, este artigo propõe-se a examinar a tese cética que sustenta que, diante da impossibilidade de decidir racionalmente entre duas posições excludentes, o mais prudente ou a única coisa raiconal é suspender o juízo. Expomos a ideia de que a fonte do ceticismo não é a vida ordinária, o que impossibilita que o desacordo real entre pares epistêmicos constitua seu fundamento. Pretendemos mostrar que os cenários céticos diferem ontologicamente dos cenários cotidianos, sem que essa diferença ontológica implique uma diferença epistêmica, pois as práticas epistêmicas não variam de um cenário cético a outros tipos de cenário.

Palavras-chave: Desacordo; ceticismo; argumento mooreano; contextualismo; evidência.

Principia 16(1): 81-97 (2012). 


\section{Notas}

${ }^{1}$ Prácticas en las que $p$ es conocido por $S$ de una manera que depende constitutivamente en las experiencias de $S$. Es decir, que si $p$ es parte de la evidencia de $S$, no debería ser posible para $S$ saber que $p$ es parte de la evidencia de $S$ solamente mediante una introspección $a$ priori o únicamente a través de o la reflexión.

${ }^{2}$ Por supuesto, esto no quita que no podamos indagar acerca de la fiabilidad de las fuentes del conocimiento. De hecho, el escepticismo es producto de semejante indagación.

${ }^{3}$ La tesis mooreana sobre el conocimiento perceptual inmediato puede asimilarse al problema de la viabilidad del fundacionismo. Sin embargo, son diferentes ya que el fundacionismo es una tesis acerca de la arquitectura de la razón en general, mientras que la tesis mooreana funciona en el contexto de la vida diaria: se puede reconocer creencias basadas en la percepción, sin la necesidad de reconocer que son o que descansan en creencias básicas.

${ }^{4}$ La conclusión que a la que llega Feldman es que resulta razonable pensar que uno puede renunciar a las creencias que posee en virtud de otras que están mejor fundamentadas. Esto implica que los escépticos y los sujetos con los que no se está de acuerdo, pueden socavar el conocimiento ordinario y la justificación.

${ }^{5}$ Así, el escéptico y el mooreano usan el término "sabe" rigiéndose por sus condiciones de verdad, teniendo en cuenta un solo marcador de registros cuando sus demandas son hechas. Esta imagen, por supuesto, promueve la idea de que el escéptico y su oponente en realidad se contradicen entre sí. Pero si no hubiera un marcador único, el escéptico no negaría precisamente lo que su oponente está afirmando y no habría debate de ida y vuelta. ${ }^{6}$ Una reacción reciente contra este tipo de conservadurismo - y a favor del argumento mooreano - puede encontrarse en Willenken (2011). Por otro lado, Pryor (2004), sostiene en contra de este conservadurismo cierto liberalismo. La teoría que trata liberalmente una hipótesis $H$ niega que para tener, prima facie, una justificación para creer $p$ se necesite una justificación antecedente para creer $H$. No obstante, sí tiene importancia no- $H$, como una hipótesis socava pruebas en contra de $H$ y con ello socava la justificación prima facie para creer que $p$. Dicho de otra manera, no es el caso que cada vez que la experiencia visual $E$ le da una justificación para creer su contenido $p$, esta experiencia deba incluir una justificación independiente que incluya la creencia de otras proposiciones (cfr. Silins 2007).

${ }^{7}$ Para la defensa de este punto de vista, véase: Elga (2007) y Christensen (2007).

${ }^{8}$ Para la defensa de este punto de vista, véase: Kelly (2005).

${ }^{9}$ Puesto que, una vez más, para $S$ es lo mismo apelar a un proceso fiable habitando el mundo real o el mundo virtual para justificar sus creencias.

${ }^{10}$ Cohen (1984) también sugirió que lo que justifica nuestras creencias, debe ser común a un sujeto que tenga conocimiento y al duplicado interno que es engañado por un genio maligno.

${ }^{11}$ El hecho de que no se conozcan filósofos contemporáneos que adscriban realmente al escepticismo no es poco relevante. Esto quiere decir que el escepticismo se toma con un desafío para la reflexión acerca del alcance del conocimiento.

${ }^{12}$ El presente texto ha sido realizado en el marco de las actividades del Proyecto de Investigación FFI2009-08557/FISO, financiado por el Ministerio de Ciencia e Innovación del Gobierno de España.

Principia 16(1): 81-97 (2012). 